\title{
Primary Cutaneous Diffuse Large B-Cell Lymphoma of the Leg: Apropos of
} a Fatal Case

Martinez Peinado Carmen ${ }^{*}$, Valenzuela Salas Ignacio', Nogueras Morillas Paloma', Aneiros Fernández José2, Blasco Morente Gonzalo', Garrido Colmenero Cristina ${ }^{1}$, Martínez García Eliseo ${ }^{1}$ and Puerta Puerta José Manuel ${ }^{3}$

${ }^{1}$ Department of Department of Dermatology, Hospital Virgen de las Nieves, Granada, Spain

${ }^{2}$ Department of Dermatopathology, Hospital Virgen de las Nieves, Granada, Spain

${ }^{3}$ Department of Hematology, Hospital Virgen de las Nieves, Granada, Spain

\begin{abstract}
Primary cutaneous lymphomas are a heterogeneous group of lymphoproliferative disorders with skin involvement and no evidence of systemic disease at the time of diagnosis. Since the 1980s, primary cutaneous B-cell lymphomas have been considered a specific group of lymphomas. Large B-cell lymphoma of the leg accounts for $2 \%$ of primary cutaneous lymphomas, but its classification has been under debate over the past few years. It was recognized as an independent entity in the 2004 WHO-EORTC classification of cutaneous lymphomas. It is clinically characterized by erythematous nodules or tumors, frequently unilateral, on the distal third of the lower limbs in patients of advanced age. The clinical behavior is generally indolent, and cases of extracutaneous spread are infrequent but have an intermediate prognosis. We report the case of an 85-yr-old man who presented with a six-week history of asymptomatic indurated erythematous plaque on the left leg that had rapidly and progressively increased in size. Histological analysis revealed a CD20- and bcl-2-positive large cell lymphoid infiltrate throughout the dermis. The extension study was normal. Chemotherapy was started with the R-CHOPregimen, and the patient evidenced a good clinical response but died after two months.
\end{abstract}

Keywords: B-cell lymphoma; Primary cutaneous lymphoma; B-cell cutaneous lymphoma; Treatment

\section{Introduction}

Primary cutaneous B-cell lymphomas (PCBCLs) are recognized as an independent category within non-Hodgkin lymphomas andare distinguished from T-cell lymphomas and secondary cutaneous B-cell lymphomas. They form a heterogeneous subgroup of non-Hodgkin's skin lymphomas with no evidence of systemic disease at the time of diagnosis [1]. They account for $20-25 \%$ of all cutaneous lymphomas and generally show an indolent clinical behavior. Cutaneous recurrence is not uncommon, butthere have been few reports of extracutaneous spread of the disease $[2,3]$.

There was considerable debate about the definition of PCLs for some time, with differences between classifications published by the World Health Organization (WHO) and European Organization for Research and Treatment of Cancer (EORTC). However, a joint WHOEORTC classification of cutaneous lymphomas was published in 2004 [1,4], defining the main types of PCBCL as: primary cutaneous marginal zone B-cell lymphoma (PCMZL), primary cutaneous follicle center lymphoma (PCFCL) and primary cutaneous diffuse large B-cell lymphoma, leg type (PCDLBCL-LT), and other primary cutaneous diffuse large B-cell lymphomas (PCDLBCLs). PCMZL and PCFCL are non-aggressive, with a 5 -year survival rate $>95 \%$ and extracutaneous spread is rare, although recurrence is common. PCDLBCL-LT is less frequent but more aggressive and has an intermediate prognosis, with a 5 -year survival rate $<60 \%$.

Large B-cell lymphoma of the leg represents $2 \%$ of primary cutaneous lymphomas and preferentially appears in patients of advanced age, with a slight predominance in women. It is usually characterized by asymptomatic erythematous nodules or tumors on the distal third of lower limbs, frequently unilateral and with a tendency to necrosis; the prognosis is intermediate [5]. The treatment of choice is surgery or radiotherapy in patients with isolated lesions, and chemotherapy in those with multiple or recurrent lesions, mainly with the CHOP regimen (cyclophosphamide, doxorubicin, vincristine and prednisone).
Rituximab has recently been used as a therapeutic alternative, alone or combined with this regimen, in patients with recurrent lesions or multiple diseases. We report the case of a patient with an aggressive LBCLL who was treated with Rituximab-CHOP chemotherapy and showed a good initial response but died after two months.

\section{Case Report}

An 85-yr-old male with a history of laryngeal cancer, chronic bronchitis, and hypertension was referred to our department at six weeks after the onset of an asymptomatic lesion on the left leg that had rapidly increased in size. Physical examination revealed an erythematous-violaceous plaque of around $8 \mathrm{~cm}$ on the posterolateral side of the left leg that was well-defined and indurated on palpation; similar but smaller nodules were observed in close proximity. All lesions were located on a more diffuse erythematous area (Figure 1). No other cutaneous manifestations were detected and there was no palpable locoregional lymphadenopathy or visceromegaly.

The histopathological study of a cutaneous biopsy specimen of the lesion showed lymphoid-type neoformation with a diffuse growth pattern that involved the dermis and hypodermis but not the epidermis (Figure 2A), observing cells with large nuclei and marginal nucleoli (immunoblasts and centroblasts). Immunohistochemical study of the

*Corresponding author: Martinez Peinado Carmen, Department of Dermatology, Hospital Virgen de las Nieves, C/Emilia Pardo Bazán 8, P-14, $2^{\circ} \mathrm{A}$, 18013 Granada, Spain, Tel: (+34)662485740; E-mail: carpeinado@hotmail.es

Received November 20, 2013; Accepted December 11, 2013; Published December 15, 2013

Citation: Carmen MP, Ignacio VS, Paloma NM, José AF, Gonzalo BM, et al. (2013) Primary Cutaneous Diffuse Large B-Cell Lymphoma of the Leg Apropos of a Fatal Case. J Blood Disorders Transf 5: 181. doi: 10.4172/21559864.1000181

Copyright: (c) 2013 Carmen MP, et al. This is an open-access article distributed under the terms of the Creative Commons Attribution License, which permits unrestricted use, distribution, and reproduction in any medium, provided the original author and source are credited. 
Citation: Carmen MP, Ignacio VS, Paloma NM, José AF, Gonzalo BM, et al. (2013) Primary Cutaneous Diffuse Large B-Cell Lymphoma of the Leg: Apropos of a Fatal Case. J Blood Disorders Transf 5: 181. doi: 10.4172/2155-9864.1000181

Page 2 of 3

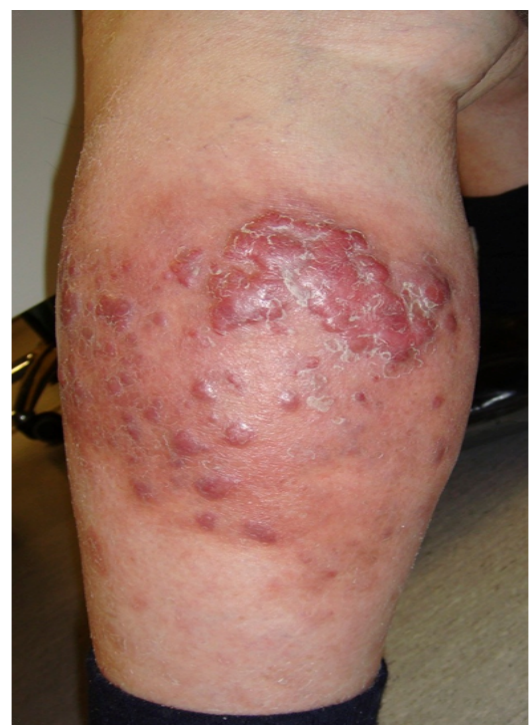

Figure 1: Erythematous-violaceus and infiltrated plaque on posterolateral left leg with similar nodules in proximity.

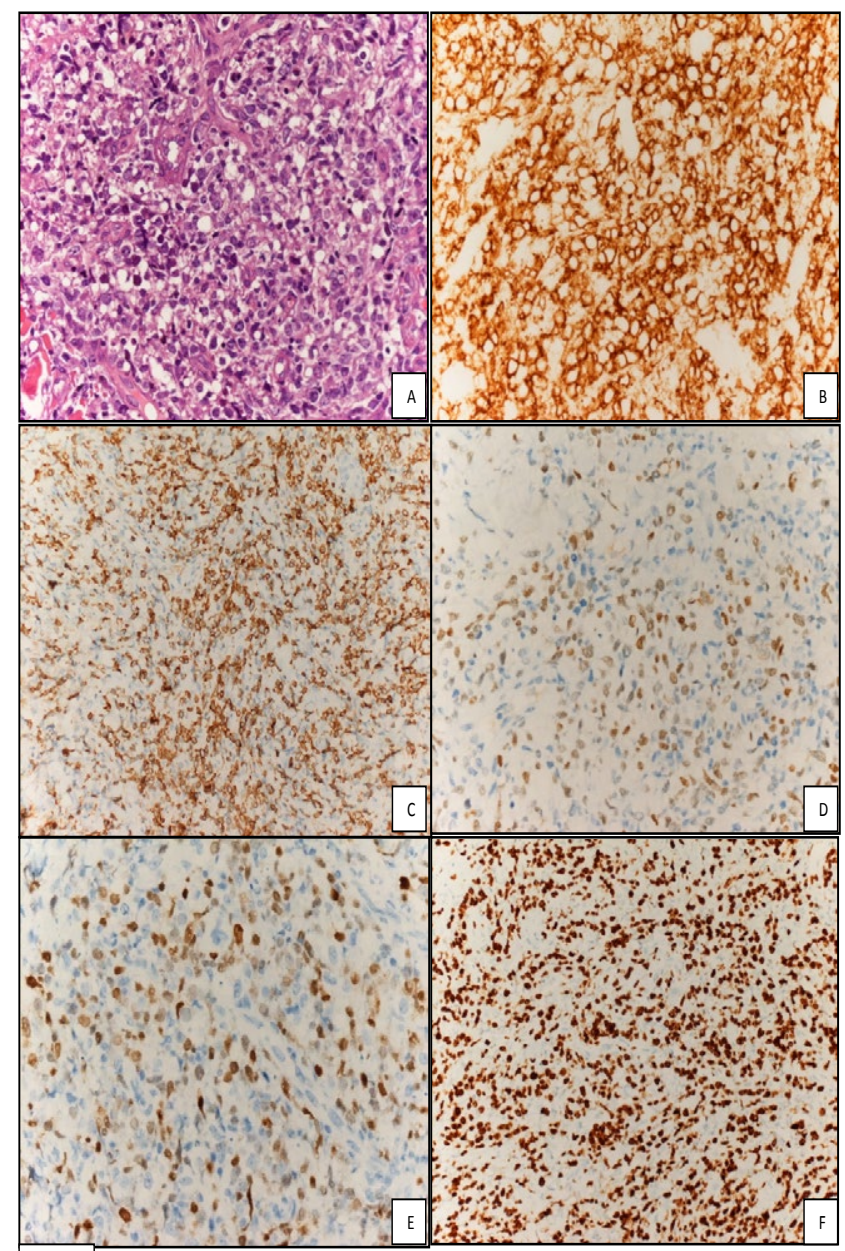

Figure 2: (A) Diffuse cellular infiltrate of atypical cells (Hematoxylin-eosin original magnification $\mathrm{x} 200$ ). Immunohistochemical study: (B) postivity for CD20, (C) positivity for Bcl-2, (D) positivity for Bcl-6, (E) positivity for MUM-1, (F) Ki-67 $>70 \%$ activity. tumor cells evidenced positivity for CD20, CD 79a, Bcl-2, Bcl-6, and MUM-1 and negativity for CD10, CD5, CD138 and CD30; more than $70 \%$ showed Ki-67 activity (Figure 2B-2F). These findings confirmed the diagnosis of PCDLBCL-LT.

Systemic involvement was ruled out by the results of the extension study, which included a full blood count, analyses of globular sedimentation rate, biochemistry, $\beta_{2}$-microglobulin, and lactate dehydrogenase, positron emission tomography-computed tomography imaging, and bone marrow puncture-aspiration.

During the time period in which the above tests were carried out, the lesion continued to grow rapidly, acquiring tumor morphology and reaching a size of $15 \mathrm{~cm}$ (Figure 3). Chemotherapy was started with the R-CHOP regimen $\left(375 \mathrm{mg} / \mathrm{m}^{2}\right.$ rituximab plus $750 \mathrm{mg} / \mathrm{m}^{2}$ cyclophosphamide, $50 \mathrm{mg} / \mathrm{m}^{2}$ adriamycin, $1.4 \mathrm{mg} / \mathrm{m}^{2}$ vincristine and $100 \mathrm{mg}$ prednisone) in 21-day cycles. The patient showed a good initial clinical response to this treatment. However, the patient developed toxic pancytopenia after the third cycle and was admitted to hospital, where his general status worsened and he died from multiple organ dysfunction.

\section{Comment}

Cutaneous B-cell lymphomas account for $20-25 \%$ of primary cutaneous lymphomas and are usually centrofollicular and marginal zone lymphomas-immunocytomas. Large B-cell lymphoma of the leg is much less frequent and shows a distinct clinical presentation and/ or behavior [6]. The definitions of PCBCL types in the 2004 WHOEORTC classification allow more reliable diagnoses to be made and facilitate clinical decision-making, and they have generally been substantiated by evidence emerging from Immunologic and molecular genetic studies [7].

PCDLBCL-LT is an aggressive subtype of PCBCL that appears on the distal third of the lower limb or, in $10-15 \%$ of patients, at other anatomic sites. It preferentially affects females (female:male ratio of 2:1) and the elderly (mean age of $76 \mathrm{yrs)} \mathrm{[8].} \mathrm{The} \mathrm{most} \mathrm{frequent}$ presentation is as a red-purplish nodule or tumor in one or both legs, as in the present case. Atypical forms include verrucous plaques, multiple

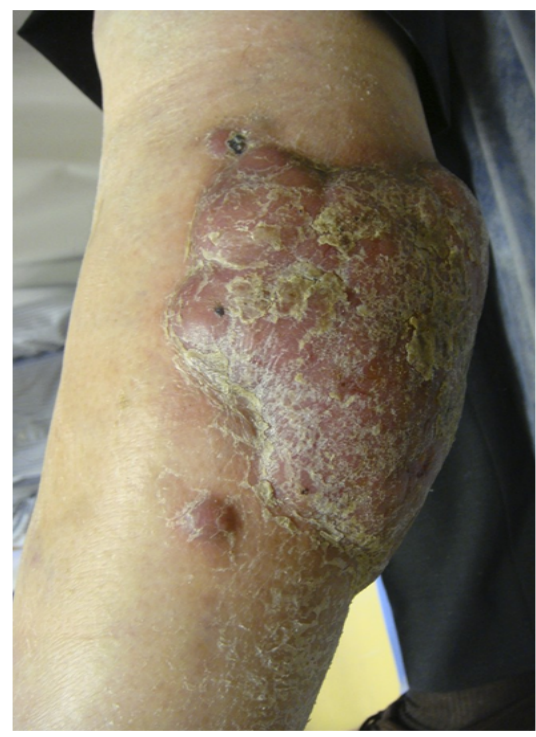

Figure 3: Well demarcated and infiltrated tumor showing the rapid growth of the initial lesion. 
garland-like nodules, or even lesions that resemble a chronic venous ulcer [9]. Extracutaneous spread of the disease is possible and has a more unfavorable prognosis than other PCBCLs, with a 5-yr survival rate of $60 \%$ [8]. Localization in lower limbs and the presence of multiple cutaneous lesions have been associated with a poor prognosis [10]. The present patient had multiple lesions in the lower limb, but no systemic involvement was detected.

The evaluation and staging of PCBCL patients requires a complete clinical history, a physical examination, and an incisional or excisional skin biopsy that includesthe reticular dermis and subcutaneous cell tissue, because it may not be possible to differentiate PCBCL from an inflammatory process based on a superficial skin biopsy. It is recommended to complete the histopathological study with an immunophenotypic analysis of the sample and to carry out a hematological examination, including a full blood count, comprehensive profile, lactate dehydrogenase, antinuclear antibody, rapid plasma reagin, and viral hepatitis serologies. The usual test for extracutaneous spread is CT imaging, especially in patients with palpable lymphadenopathy. Positron emission tomography (PET) can contribute functional/metabolic information for the staging and for following the response to treatment, while an integrated PET-CT scan provides simultaneous anatomic and functional/metabolic information on tumor spread and involvement. A biopsy should be performed on any lymph node $>1.5 \mathrm{~cm}$ in length on imaging study or with elevated PET activity. Consideration should also be given to a bone marrow biopsy, serum protein and immunoglobulin electrophoresis, and peripheral blood flow cytometry [11].

The histological study shows a diffuse dermal infiltrate formed by large centroblast/immunoblast-like cells in PCDBCLs, which sometimes appear in monotonous or confluent sheets. Mitotic figures anda high proliferative index are frequently observed. The cells have a round nucleus more than twice the size of a normal lymphocyte nucleus and open chromatin with prominent nucleoli [11]. The characteristic immunophenotype of PCDLBCL-LT is CD20+, CD79+, CD10-, $\mathrm{Bcl}-2+$, and $\mathrm{Bcl}-6+/-$. Unlike in PCFCL, there is a strong expression of Bcl-2, MUM1/IRF4, and FOX-P1 PCDLBCL-LT. Some authors have proposed that any PCDBCL with Bcl-2 and MUM1 expression should be consideredleg type, regardless of the localization [11]. The expression of bcl-2 oncogene reduces the disease-free survival, and the prognosis is worse for lymphomas that express than those that do not [12-14]. Some authors have even described the expression of bcl-2 protein as the most important independent survival prognosis factor in cutaneous large B-cell lymphomas [15]. In the present patient, the immunohistochemical study showed positivity for CD20, CD79a, bcl-2, bcl-6, and MUM-1 and negativity for CD10, CD5, CD138, and CD30, confirming the diagnosis of PCDLBCL-LT.

Therapeutic options for PCDLBCL-LT are limited, due to its low frequency and the consequent lack of novel therapies and prospective randomized clinical trials. The European Organization for Research and Treatment of Cancer Cutaneous Lymphoma Group (EORTCCLG) and the International Society for Cutaneous Lymphoma (ISCL) have developed standard protocols for the treatment of the three main types of PCBCL, based on the literature and good clinical practice [16]. Radiation therapy (RT) and R-CHOP are the first-line treatment for solitary, localized, or generalized disease $[11,17]$. The R-CHOP chemotherapeutic regimen was indicated in the present patient due to his clinical characteristics. The initial response to treatment was positive, decreasing tumor size, but he died after two months from severe pancytopenia and subsequent multi-organ dysfunction. The initially favorable therapeutic response of the tumor and the absence of radiographic evidence of extracutaneous spread suggest that the death was caused by a complication secondary to the chemotherapeutic treatment rather than by the disease itself.

\section{References}

1. Willemze R, Jaffe ES, Burg G, Cerroni L, Berti E, et al. (2005) WHO-EORTC classification for cutaneous lymphomas. Blood 105: 3768-3785.

2. Gallardo F, Pujol RM (2004) Diagnóstico y tratamiento de los linfomascutáneos primarios de células B. Actas Dermatosifiliogr 95: 537-547.

3. Servitje O, Gallardo F, Estrach T, Pujol RM, Blanco A, et al. (2002) Primary cutaneous marginal zone B-cell lymphoma: a clinical, histopathological, immunophenotypic and molecular genetic study of 22 cases. $\mathrm{Br} \mathrm{J}$ Dermatol 147: 1147-1158.

4. Park JH, Shin HT, Lee DY, Lee JH, Yang JM, et al. (2012) World Health Organization-European Organization for Research and Treatment of Cancer classification of cutaneous lymphoma in Korea: a retrospective study at a single tertiary institution. J Am Acad Dermatol 67: 1200-1209.

5. Goodlad JR, Krajewski AS, Batstone PJ, McKay P, White JM, et al. (2003) Primary cutaneous diffuse large B-cell lymphoma: prognostic significance of clinicopathological subtypes. Am J Surg Pathol 27: 1538-1545.

6. Hernández-Machín B, Fernández-Misa R, Alfonso JL, Maeso MC, Marrero $C$, et al. (2005) [Primary cutaneous diffuse large B-cell lymphoma of the leg according to the new WHO-EORTC classification. Two cases]. Actas Dermosifiliogr 96: 607-611.

7. Khamaysi Z, Ben-Arieh Y, Izhak OB, Epelbaum R, Dann EJ, et al. (2008) The applicability of the new WHO-EORTC classification of primary cutaneous lymphomas to a single referral center. Am J Dermatopathol 30: 37-44.

8. Pedraz J, Delgado Y, Ballestero M, Fraga J, García-DíezA, et al. (2005) [Cutaneous large B-cell lymphoma of the leg]. Actas Dermosifiliogr 96: 237-240.

9. Garbea A, Dippel E, Hildenbrand R, Bleyl U, Schadendorf D, et al. (2002) Cutaneous large B-cell lymphoma of the leg masquerading as a chronic venous ulcer. Br J Dermatol 146: 144-147.

10. Grange F, Beylot-Barry M, Courville P, Maubec E, Bagot M, et al. (2007) Primary cutaneous diffuse large B-cell lymphoma, leg type: clinicopathologic features and prognostic analysis in 60 cases. Arch Dermatol 143: 1144-1150.

11. Suárez AL, Querfeld C, Horwitz S, Pulitzer M, Moskowitz A, et al. (2013) Primary cutaneous B-cell lymphomas: part II. Therapy and future directions. J Am Acad Dermatol 69: 343

12. Hermine O, Haioun C, Lepage E, d'Agay MF, Briere J, et al. (1996) Prognostic significance of bcl-2 protein expression in aggressive non-Hodgkin's lymphoma. Groupe d'Etude des Lymphomes de l'Adulte (GELA). Blood 87: 265-272.

13. Hill ME, MacLennan KA, Cunningham DC, Vaughan Hudson B, Burke M, et al. (1996) Prognostic significance of BCL-2 expression and bcl-2 major breakpoint region rearrangement in diffuse large cell non-Hodgkin's lymphoma: a British National Lymphoma Investigation Study. Blood 88: 1046-1051.

14. Kramer MH, Hermans J, Parker J, Krol AD, Kluin-Nelemans JC, et al. (1996) Clinical significance of bcl2 and p53 protein expression in diffuse large B-cell lymphoma: a population-based study. J Clin Oncol 14: 2131-2138.

15. Grange F, Petrella T, Beylot-Barry M, Joly P, D'Incan M, et al. (2004) Bcl-2 protein expression is the strongest independent prognostic factor of survival in primary cutaneous large B-cell lymphomas. Blood 103: 3662-3668.

16. Senff NJ, Noordijk EM, Kim YH, Bagot M, Berti E, et al. (2008) European Organization for Research and Treatment of Cancer and International Society for Cutaneous Lymphoma consensus recommendations for the management of cutaneous B-cell lymphomas. Blood 112: 1600-1609.

17. Pedraz J, Delgado Y, Aragüés M, Fraga J, García-Díez A, et al. (2005) [Cutaneous marginal zone B-cell lymphoma treated with rituximab]. Actas Dermosifiliogr 96: 593-597.

Citation: Carmen MP, Ignacio VS, Paloma NM, José AF, Gonzalo BM et al. (2013) Primary Cutaneous Diffuse Large B-Cell Lymphoma of the Leg: Apropos of a Fatal Case. J Blood Disorders Transf 5: 181. doi: 10.4172/2155-9864.1000181 